\title{
Princípios físicos do Doppler em ultra-sonografia
}

\author{
Physical principles of Doppler ultrasonography
}

\author{
Cibele Figueira Carvalho $^{* \text { IIII }}$ Maria Cristina Chammas ${ }^{\text {II }}$ Giovanni Guido Cerri ${ }^{\text {II }}$
}

\section{- REVISÃO BIBLIOGRÁFICA -}

\section{RESUMO}

A ultra-sonografia Doppler é um método relativamente recente dentro da rotina veterinária que fornece informações em tempo real da arquitetura vascular e dos aspectos hemodinâmicos dos vasos sanguíneos examinados em diversos órgãos vitais. Pode determinar a presença, a direção e o tipo de fluxo sanguíneo. Esta revisão de literatura compila as informações sobre os princípios físicos da ultrasonografia Doppler. A ampliação do conhecimento desta tecnologia possibilita a melhor compreensão das aplicações $e$ limitações deste método diagnóstico, que tem se tornado rotina na medicina veterinária de pequenos animais.

Palavras-chave: ultra-sonografia, Doppler, artefato, vascularização.

\section{ABSTRACT}

Doppler ultrasonography is a relatively new diagnostic tool in veterinary medicine that provides real time details about vascular architecture and hemodynamic aspects of examinated blood vessels in several internal organs. Doppler can identify the presence, direction and type of blood flow. This literature review provides information about the physical principles of Doppler ultrasonography. The enlargement of expertise about this technology lead to a better comprehension of its use and limitations as a diagnostic technique, which already becomes usual in veterinary medicine of small animals.

Key words: ultrasonography, Doppler, artifact, vascularization.

\section{INTRODUÇÃO}

A ultra-sonografia Doppler é um método relativamente recente em Medicina Veterinária. A ferramenta Doppler associada à ultra-sonografia convencional fornece informações em tempo real sobre a arquitetura vascular e os aspectos hemodinâmicos dos vasos em diversos órgãos. O conhecimento dos princípios físicos básicos desta técnica auxilia na compreensão do método. Há poucos artigos na literatura veterinária sobre o tema. Assim, este trabalho tem como objetivo revisar as principais informações sobre os princípios físicos do Doppler para possibilitar o melhor entendimento deste método, que já começa a ser usado na rotina veterinária em pequenos animais.

Histórico e fundamentos da técnica Doppler

Em 1842, Christian Johann Doppler descreve a situação na qual uma fonte de ondas (sonoras ou eletromagnéticas), que está em movimento em relação a um receptor, altera a freqüência de onda durante este processo, aumentando a freqüência durante a aproximação da fonte e diminuindo durante o seu distanciamento (KAWAKAMA et al., 1993). Assim, na ultra-sonografia, o chamado efeito Doppler pode ser definido como sendo o princípio físico no qual se verifica a alteração da freqüência das ondas sonoras

IServiço de ultra-sonografia, Instituto Brasileiro de Diagnóstico e Especialidades Veterinárias Provet, São Paulo, SP, Brasil.

IIInstituto de Radiologia do Hospital das Clínicas, Faculdade de Medicina, Universidade de São Paulo (USP), São Paulo, SP, Brasil.

*Endereço para correspondência: Travessa Leon Berry, 122, Jardim Paulista, 01402-030. Tel.: (11) 38842168. Fax.: (11) 3885 1194. São Paulo, SP, Brasil. E-mail: cibelefcarvalho@terra.com.br. 
refletidas quando o objeto (corpo) refletor se move em relação a uma fonte de onda sonora. Supondo que o transdutor do equipamento capte o movimento de um objeto analisado, deve-se esperar um deslocamento da freqüência incidente sobre o objeto, promovendo aumento da resposta quando ambos se aproximam e redução quando se afastam. No âmbito médico e veterinário, este efeito é usado durante o exame dos vasos sanguíneos. As hemácias em movimento dentro dos vasos, ao encontrarem uma onda sonora, comportam-se como corpos refletores. O estudo por meio do Doppler registra o movimento do sangue no sistema cardiovascular (FEIGENBAUM, 1986; VERMILLON,1997). A diferença entre a freqüência do som transmitido (ft) e a daquele refletido (fr) é chamada deslocamento de freqüência Doppler (fd) (SZATMARI et al., 2001). Se o sentido do fluxo sanguíneo for na direção do transdutor, então a fd será positiva, isto é, o eco retornado terá uma freqüência mais alta. Se a direção do fluxo sangüíneo for no sentido contrário ao do transdutor, então a fd será negativa (isto é, a freqüência do ultra-som refletido é mais baixa do que aquela transmitida). Assim, a velocidade de aproximação do objeto será a componente vetorial do movimento paralela ao feixe sonoro, proporcional ao co-seno do ângulo de aproximação (CERRI et al., 1998).

Pode-se observar também que a velocidade detectável pelo método é uma função inversamente proporcional à freqüência emitida pelo transdutor. Assim, para se observar em velocidades altas, necessariamente utilizar-se-á freqüências mais baixas que as aplicadas para os modos bidimensionais (CERRI et al., 1998).

O deslocamento Doppler é demonstrado de vários modos dependendo da técnica utilizada. Usando-se modo Doppler pulsado, as ondas sonoras são transmitidas como um impulso, sendo que um traçado pode ser visto e simultaneamente um som pode ser ouvido. Usando Doppler colorido, o deslocamento de freqüência (fd) é demonstrado como um espectro de uma ou duas cores dentro de uma área definida (caixa colorida). A equação Doppler ( $\mathrm{fd}=2 \mathrm{ft} . \mathrm{v} \cdot \cos \theta / \mathrm{c}$ ) contém parâmetros que influenciam a magnitude do deslocamento de freqüência Doppler (fd) (Figura 1): $\mathrm{ft}=$ freqüência do feixe ultra-sônico transmitido (freqüência do transdutor); v=velocidade das hemácias (alvo móvel); $\theta$ =ângulo Doppler (ângulo formado pela intersecção do eixo correspondente à direção do fluxo

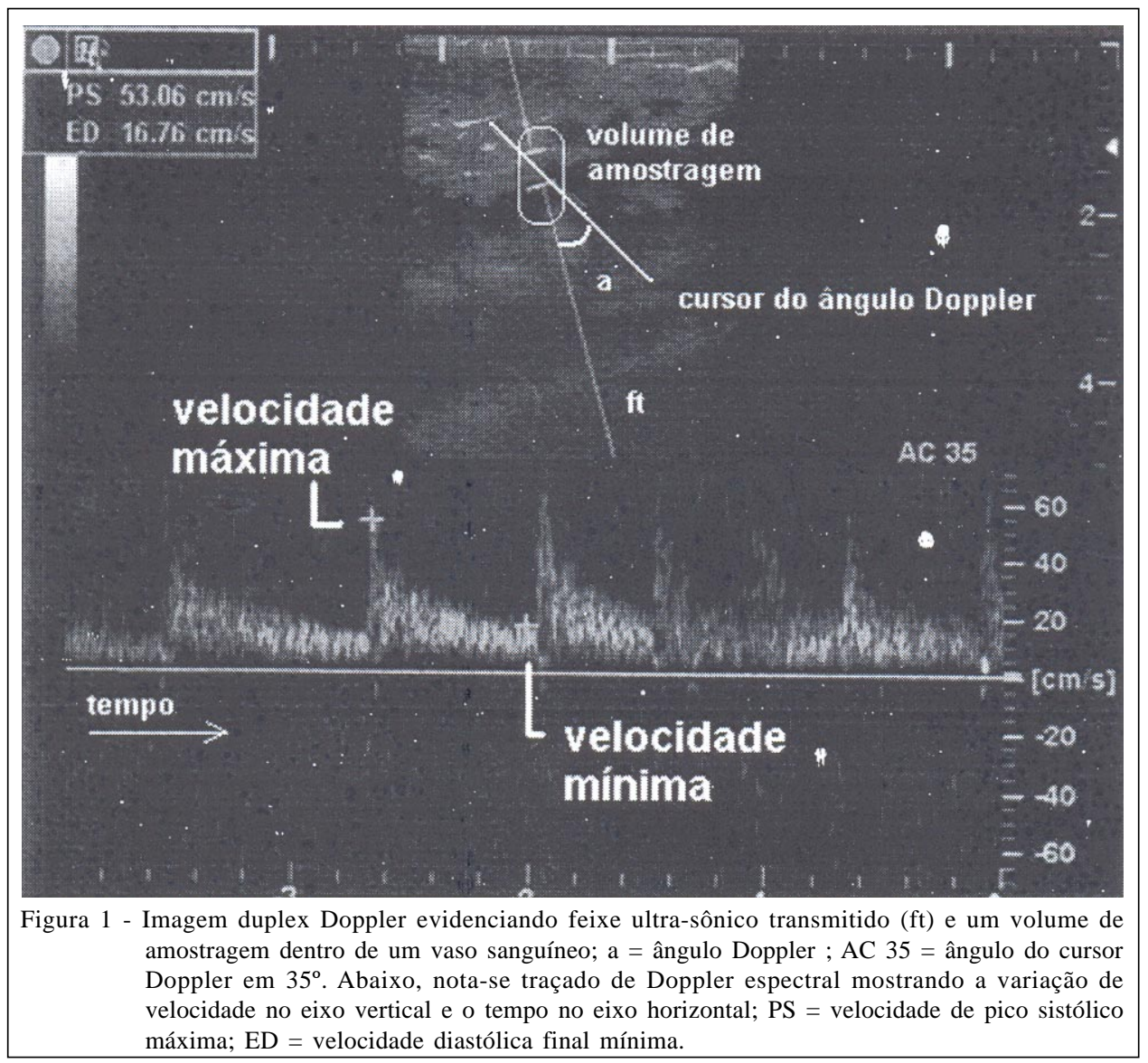

Ciência Rural, v.38, n.3, mai-jun, 2008. 
sanguíneo dentro do vaso e o feixe sonoro); $\cos \theta=\mathrm{CO}-$ seno do ângulo formado entre o transdutor e as hemácias; c=velocidade média do ultra-som nos tecidos $\left(1540 \mathrm{~m} \cdot \mathrm{s}^{-1}\right)$. Através da fórmula Doppler, é estabelecida a velocidade da corrente sangüínea.

A magnitude da mudança de freqüência (deslocamento Doppler) é maior quando o feixe sonoro e o eixo formado pelo vaso sanguíneo são paralelos $\left(\theta=0^{\circ}, \cos \theta=1\right)$. Não há deslocamento Doppler se eles forem perpendiculares um ao outro $\left(\theta=90^{\circ}, \cos \theta=0\right)$ (POULSEN NAUTRUP, 2001). Daí a importância da utilização de uma técnica adequada para se obterem dados fidedignos de velocidade de fluxo sangüíneo.

Alguns transdutores de uso clínico para análise espectral de Doppler utilizam um feixe contínuo de ultra-som (Doppler contínuo). O resultado final é um sinal composto que apresenta a variação de velocidade de todos os elementos móveis atravessados pelo feixe, trazendo alguma dificuldade na interpretação do sinal. Para contornar esta dificuldade, desenvolveuse a técnica de Doppler com feixe pulsado, na qual pulsos de ultra-som são emitidos, permitindo o processamento do sinal em profundidade diferente na secção estudada (SZATMARI et al., 2001). Atualmente, o Doppler contínuo é utilizado em cardiologia e o pulsado tem aplicações em medicina interna e vascular.

\section{Doppler pulsado ou espectral}

Um transdutor de Doppler pulsado contém um cristal piezelétrico que transmite ondas curtas de ultra-som (pulsos) em intervalos regulares e recebe o sinal refletido no resto do tempo, comparando-o com aquele transmitido. A onda pulsada permite ao Doppler medir uma região específica dentro de um campo de imagem, possibilitando assim a medida da velocidade dentro dos vasos selecionados. A freqüência com a qual os pulsos (sinais) são emitidos por segundo é chamada de freqüência de repetição de pulso (PRF). O tempo entre o pulso e o eco depende do local de reflexão, embora seja possível localizar a fonte do eco retornado. Esta técnica permite precisar a localização do volume de tecido do qual o sinal Doppler de fluxo sanguíneo foi coletado, ao contrário do que ocorre com a técnica de Doppler contínuo. A região onde os sinais Doppler são mensurados é chamada de volume de amostra (ou gate). A freqüência de repetição de pulso ultra-sônico (PRF) introduziu novo parâmetro para a realização do exame, pois determina a freqüência Doppler máxima detectável pelo equipamento sem ambigüidades (SZATMARI et al., 2001; YANIK,2002). A freqüência máxima amostrável sem ambigüidades é chamada freqüência de Nyquist e o fenômeno de ambigüidade é conhecido como aliasing (do latim alias=de outra forma; neste caso, de outra cor). A freqüência de Nyquist (fN) é obtida através da fórmula: $\mathrm{fN}=\mathrm{PRF} / 2$. Ou seja, toda vez que a freqüência de deslocamento Doppler for maior que PRF/2 ocorrerá ambigüidade no sinal detectado, que se expressará no espectro de freqüências, como a apresentação das maiores freqüências reversas ou com sinal contrário, abaixo da linha de base (CERRI et al., 1998).

Após a aquisição dos ecos sonoros, o processamento do sinal realiza a transformação das várias ondas de freqüências diferentes, num espectro de freqüências, através de um procedimento matemático chamado transformação de Fourier. O sistema de processamento distribuirá as freqüências de deslocamento Doppler num gráfico, levando em conta as densidades de freqüência, ou seja, o número de ondas apresentadas numa mesma freqüência (KAWAKAMA et al., 1993). A imagem duplex combina o feixe Doppler pulsado com a imagem bidimensional em tempo real, e a localização do volume de amostra é disposta na tela. O volume de amostra pode ser movido para dentro do lúmen de um vaso ao mesmo tempo em que ele é observado em tempo real. O tempo decorrido é avaliado no eixo horizontal ou linha de base; a freqüência de deslocamento Doppler no eixo vertical pode ser lida em KHz. Se o cursor rotacionado manualmente ficar alinhado de forma paralela ao vaso sanguíneo (ângulo de insonação), a velocidade das células em movimento (isto é, do fluxo sanguíneo) pode ser vista em cm.s-1 no eixo vertical (CERRI et al., 1998).

Convencionou-se que o fluxo em direção ao transdutor fica disposto acima da linha de base e o fluxo que vai em direção contrária ao transdutor fica disposto abaixo da linha de base. A linha base representa fluxo zero. Valores reais de velocidade podem ser obtidos somente se o ângulo Doppler não exceder $60^{\circ}$, pois um pequeno erro na estimativa do ângulo promove um grande erro acima do valor real (devido à curva do co-seno). O ângulo de insonação também pode ser corrigido com a imagem congelada (pósprocessada), mas sempre deve ser efetuado antes de medir as velocidades (YANIK,2002).

Durante o exame de duplex Doppler, a freqüência de deslocamento Doppler não é disposta somente graficamente, pois também são audíveis. As artérias têm um som parecido com um assovio ,enquanto que as veias possuem um som parecido com o vento soprando continuamente. A intensidade do som audível é diretamente proporcional à quantidade de células sanguíneas em movimento. A altura do som depende do deslocamento de freqüência Doppler. Quanto maior a velocidade do fluxo sanguíneo (isto é, mais larga a freqüência de deslocamento Doppler), mais 
audível se torna o som (SZATMARI et al., 2001). Podem-se obter informações necessárias para a interpretação dos espectros de freqüência. Essas podem ser classificadas em informações qualitativas, semiquantitativas ou quantitativas. As informações qualitativas constituem a presença ou ausência de fluxo na região analisada; são usadas na avaliação da direção e do sentido do fluxo e na avaliação da morfologia das ondas espectrais (arterial, venosa, turbulenta). As informações semiquantitativas sugerem as condições de fluxo no vaso sanguíneo amostrado de acordo com a morfologia dos espectros adquiridos. As informações quantitativas são as medidas de velocidade, em especial de máximas e mínimas, que permitem a análise da impedância e da resistividade vascular e cálculos aproximados do volume de vazão, quando associados ao modo-B. A técnica permite diferenciar o padrão Doppler característico de cada vaso sanguíneo, além das mudanças no padrão de ondas, que podem ter significado patológico (SZATMARI et al., 2001). Portanto, cada vaso apresenta uma "assinatura” ou traçado espectral característico que permite identificá-lo.

Pode-se observar que o mapeamento de freqüências de um sistema pulsado é realizado numa determinada porção do objeto amostrado (volume de amostragem), a uma profundidade determinada. Em algumas situações, o objeto de análise é muito extenso e maior que o volume de amostragem (um vaso, por exemplo). Assim, o sinal Doppler obtido será representativo somente de uma parte do objeto. Em fluxos laminares, a velocidade do fluxo varia radialmente. Nessas condições, uma amostragem realizada num pequeno volume poderá variar seu perfil espectral (sua distribuição de velocidade) do centro para a periferia do vaso. Para estes casos, desenvolveu-se um refinamento tecnológico, os denominados sistemas multigate, que, em sua configuração, apresentam várias unidades de análise em paralelo, as quais adquirem sinais isolados de deslocamento Doppler em volumes de amostragem diferentes. Pode-se analisar simultaneamente sinais de vasos localizados em profundidades diferentes do corpo ou, mantendo contíguos os diversos volume de amostragem, cobrir toda a área de secção de um vaso calibroso, obtendose uma média de amostragem de velocidades ou perfil de fluxo (CERRI et al., 1998). Os métodos mais utilizados para medir o fluxo sanguíneo em um vaso são os métodos de "insonação uniforme" (isto é, o lúmen inteiro do vaso fica incorporado ao volume amostrado) e os métodos de "máxima velocidade" em que o volume amostrado é colocado no centro do vaso (SZATMARI et al., 2001). A utilização de um ou outro método depende do calibre e da tortuosidade do vaso em estudo.

\section{Doppler colorido}

Ao contrário da técnica de Doppler pulsado, há vários volumes de amostragem dentro de uma região circunscrita (caixa colorida). O sinal obtido para cada um desses elementos de amostragem é codificado por cores em relação ao sentido do movimento e por nuances em relação ao módulo da velocidade do movimento. Sobre a imagem em tempo real é apresentada uma outra imagem, colorida, que representa um mapeamento dos elementos móveis em relação à intensidade e ao sentido do movimento (KAWAKAMA et al., 1993). O tamanho e a posição da caixa colorida no modo-B depende do (a) ultrasonografista. Dentro da caixa colorida, cada ponto móvel tem uma tonalidade de vermelho ou azul, ao invés de tons de cinza. A direção do fluxo em relação ao transdutor é ilustrada em uma barra colorida ao lado da imagem. Convencionou-se que o fluxo em direção ao transdutor é vermelho e o fluxo na direção contrária ao transdutor é azul. Os fluxos de maior velocidade são expressos por tonalidades mais claras da mesma cor (CERRI et al., 1998). Podem ser vistos fluxos de turbulência, que se expressam em forma de mosaico de cores diferentes. A técnica de Doppler colorido fornece informações sobre o movimento em uma grande parte da imagem, como um mapa. Esta técnica permite avaliar a presença, a direção e a qualidade do fluxo sanguíneo mais rapidamente do que qualquer outra técnica não invasiva, até mesmo em áreas que não aparecem como vasos no modo-B. Também é possível a diferenciação entre fluxos rápidos e lentos (SZATMARI et al., 2001).

\section{Artefatos de técnica Doppler}

“Ambigüidade do sinal detectado" Aliasing: importante artefato de técnica, que ocorre quando a velocidade do sangue excede um limite superior de medida, o chamado limite Nyquist. O limite de Nyquist é a metade da freqüência de repetição de pulso ultra-sônico (PRF). Aliasing está presente quando o PRF é menor que duas vezes a freqüência do sinal refletido da freqüência de deslocamento Doppler (CERRI et al., 1998). Nas imagens de Doppler colorido, fluxos que estão acima do limite superior medido (acima da tonalidade mais clara da cor em questão) são mostrados ou aparecem como uma cor incorreta, isto é, com a cor, que codifica a direção oposta do fluxo (ou seja, o vermelho ao invés do azul), resultando em um padrão de cor concêntrico (SZATMARI et al., 2001). No feixe Doppler espectral com aliasing, parte do espectro que está acima do limite superior fica cortada, 
e aparece erroneamente no lado oposto da linha de base como uma continuação do espectro propriamente dito (Figura 2) (CERRI et al., 1998). As soluções possíveis para isso seriam aumentar o PRF e/ou deslocar a linha de base ou ainda reduzir a freqüência do transdutor.

“Ausência de sinal Doppler”: se o eixo do ângulo de insonação entre o vaso sanguíneo e o feixe ultra-sônico estiver perpendicular um em relação ao outro, então não haverá sinal Doppler detectável (SZATMARI et al., 2001; YANIK, 2002). O vaso deverá ser observado em outra posição para se obter um ângulo mais agudo.

“Artefatos de Parede”: o filtro de parede em um sistema Doppler elimina os ecos de alta amplitude e baixa freqüência originários dos movimentos sutis de reflexão decorrentes da parede do vaso (NYLAND\& MATTOON, 2002). Isso limpa a imagem e previne que se ocultem ecos de baixa amplitude e alta freqüência decorrentes de fluxos sanguíneos. No entanto, o uso impróprio do filtro de parede pode também remover sinais de fluxo de baixa velocidade e resultar em erros de interpretação. Deve-se mantê-lo o mais baixo possível, geralmente entre 50 e $100 \mathrm{~Hz}$ (SZATMARI et al., 2001).

\section{Exame sonográfico dos vasos sanguíneos}

Durante o exame de um vaso sanguíneo, o primeiro passo é observar o vaso usando-se a técnica bidimensional e obtendo-se um plano longitudinal do mesmo (SPAULDING 1997). O eixo do feixe ultra-sônico e o eixo do vaso devem estar paralelos entre si, porém o ângulo de insonação não deve ser maior que $60^{\circ}$ (SZATMARI et al., 2001). Usando-se o modo colorido, é possível se determinar a presença ou ausência de fluxo no vaso. Os parâmetros coloridos devem ser ajustados para que o lúmen do vaso esteja preenchido somente com uma cor (isto é, sem ambigüidade de sinal detectado) e a informação colorida não ultrapasse o lúmen vascular (SZATMARI et al., 2001; NYLAND \& MATTOON, 2002). Por fim, o volume de amostra deve ser colocado em uma porção específica do vaso - de acordo com o método de velocidade máxima ou de insonação uniforme - e, usando-se a técnica Doppler pulsado, um traçado pode ser colocado nesta região particular do vaso. Se o traçado Doppler estiver livre de artefatos, a imagem deverá ser congelada e, após correção do ângulo, deve-se proceder à análise do formato das ondas (CERRI et al., 1998).

\section{Perfis ou curvas de velocidade de fluxo arterial}

A distribuição da velocidade de fluxo através do lume vascular é demonstrada através da freqüência ou do espectro de velocidade de fluxo no Doppler (também denominada OVF, ou onda de velocidade de fluxo). Os perfis de velocidade de fluxo tipo laminar são classificados em três tipos: perfil achatado (A), semiparabólico (B) e parabólico(C). Também pode ser detectado um fluxo turbulento ou turbilhonado, este com graduação variável. O fluxo sanguíneo, na maioria dos vasos, é laminar, com o sangue movendo-se em finas camadas concêntricas ou lâminas. As camadas centrais apresentam fluxo mais rápido, enquanto forças de atrito causam perda de energia e promovem a formação de camadas mais lentas próximas à parede do vaso. As hemácias movem-se à velocidade uniforme e na mesma direção. A espessura da OVF mostra a diversidade de freqüência Doppler. Segundo SZATMARI et al. (2001), os fluxos podem ser classificados em laminares ou turbulentos.

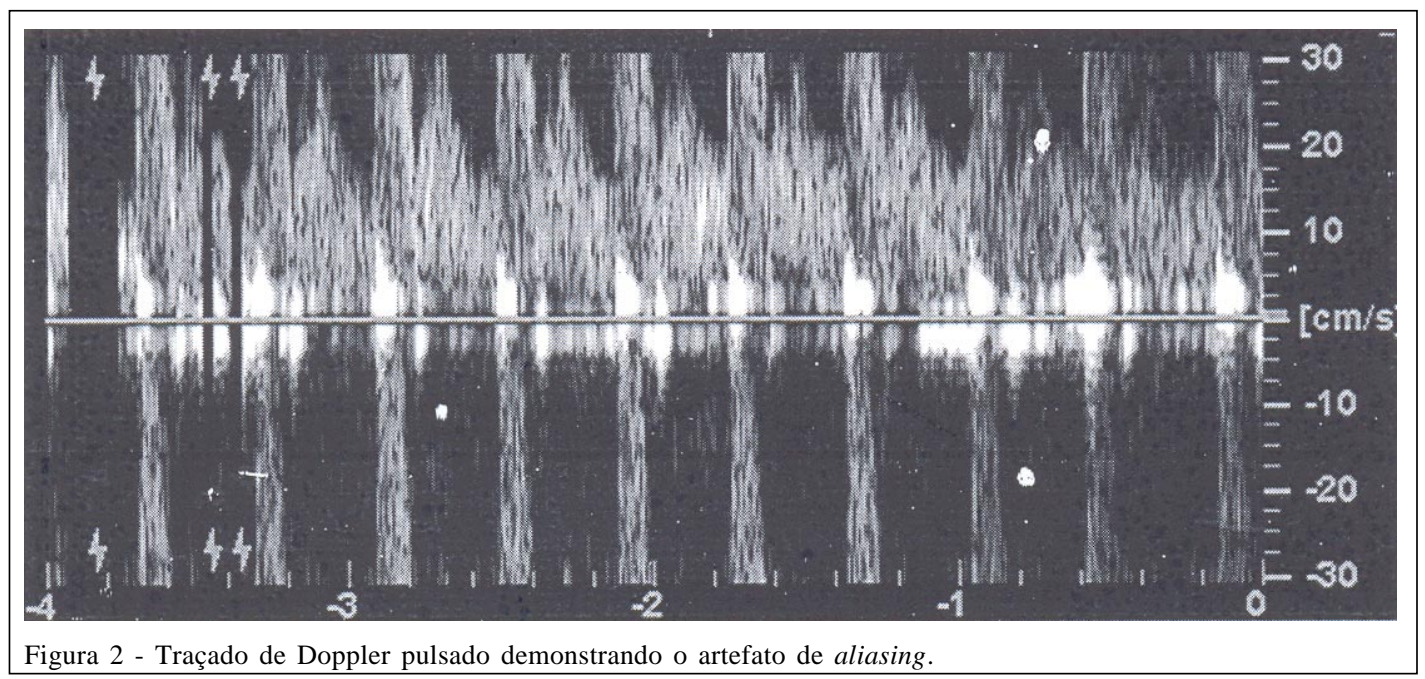

Ciência Rural, v.38, n.3, mai-jun, 2008. 
Fluxo laminar: é decorrente de uma velocidade fixa do sangue dentro de um determinado vaso. Pode apresentar perfis de velocidades diferentes (Figura 3), sendo:

A) Perfil de velocidade de fluxo achatado (plug)

Nas artérias mais calibrosas (por exemplo: a aorta), a velocidade do sangue é aproximadamente a mesma no centro do vaso e próximo à sua parede. A grande maioria das células sangüíneas move-se a uma velocidade uniforme, embora a distribuição da velocidade seja muito estreita através do lúmen vascular. Como resultado, a curva espectral de velocidade é caracterizada por uma linha fina na sístole, que promove um espaço nítido chamado janela espectral ou janela sistólica (SZATMARI et al., 2001).

B) Perfil de velocidade de fluxo semiparabólico (blunted parabolic)

Nas artérias menores (por exemplo: artéria renal), o sangue que se movimenta centralmente tem velocidade mais alta quando comparado àquele próximo da parede do vaso; então, a distribuição da velocidade é ampla através do lúmen vascular. A janela espectral não pode ser vista durante a sístole no monitor espectral, porque as células do sangue com uma variedade de velocidades (do zero ao pico de velocidade) fluem através do volume de amostragem (SZATMARI et al., 2001).

C) Perfil de velocidade de fluxo parabólico (parabolic)

Nas artérias de tamanho médio (por exemplo, tronco celíaco), o fluxo é semelhante ao perfil A no centro do vaso (isto é, as células se movimentam de maneira uniforme); no entanto, o fluxo é mais similar ao perfil $\mathrm{B}$ nas regiões periféricas do vaso. A distribuição da velocidade através do lúmen vascular tem uma amplitude intermediária (SZATMARI et al., 2001).

Fluxo turbilhonado ou turbulento: ocorre sobrepondo-se ao fluxo laminar em ocasiões onde há alteração do tamanho do vaso, velocidade do fluxo ou viscosidade do sangue. Geralmente, isso se dá em nível das bifurcações, curvas ou ramos, quando uma ampla distribuição de velocidade (isto é, espectro largo) ou até mesmo um fluxo reverso podem estar presentes, e onde células com uma grande gama de velocidades estão representadas (do zero às velocidades máximas positivas e negativas).

\section{Morfologia das ondas Doppler}

A perfusão de cada órgão determina o estado do seu leito vascular, que, por sua vez, afeta as características de fluxo dos vasos adjacentes (FINNBODNER \& HUDSON, 1998). O contorno da linha de freqüência de deslocamento Doppler máxima corresponde ao tempo de variação da máxima velocidade de fluxo dentro do vaso.

Cada contração cardíaca causa um impulso no fluxo sanguíneo e resulta na distensão das artérias. O fluxo diastólico reverso ocorre porque o sangue é rebombeado da aorta com velocidade refletida de alta impedância do leito vascular periférico dos membros posteriores. À medida que o diâmetro vascular retorna ao normal, a energia repercutida fornece o potencial necessário para promover fluxo contínuo durante a diástole. O fluxo sanguíneo das artérias supre os órgãos parenquimatosos (ex.: rins, fígado e baço), que requerem perfusão constante. Normalmente, esses órgãos apresentam fluxo contínuo, gradualmente decrescente no período diastólico e sem fluxo diastólico

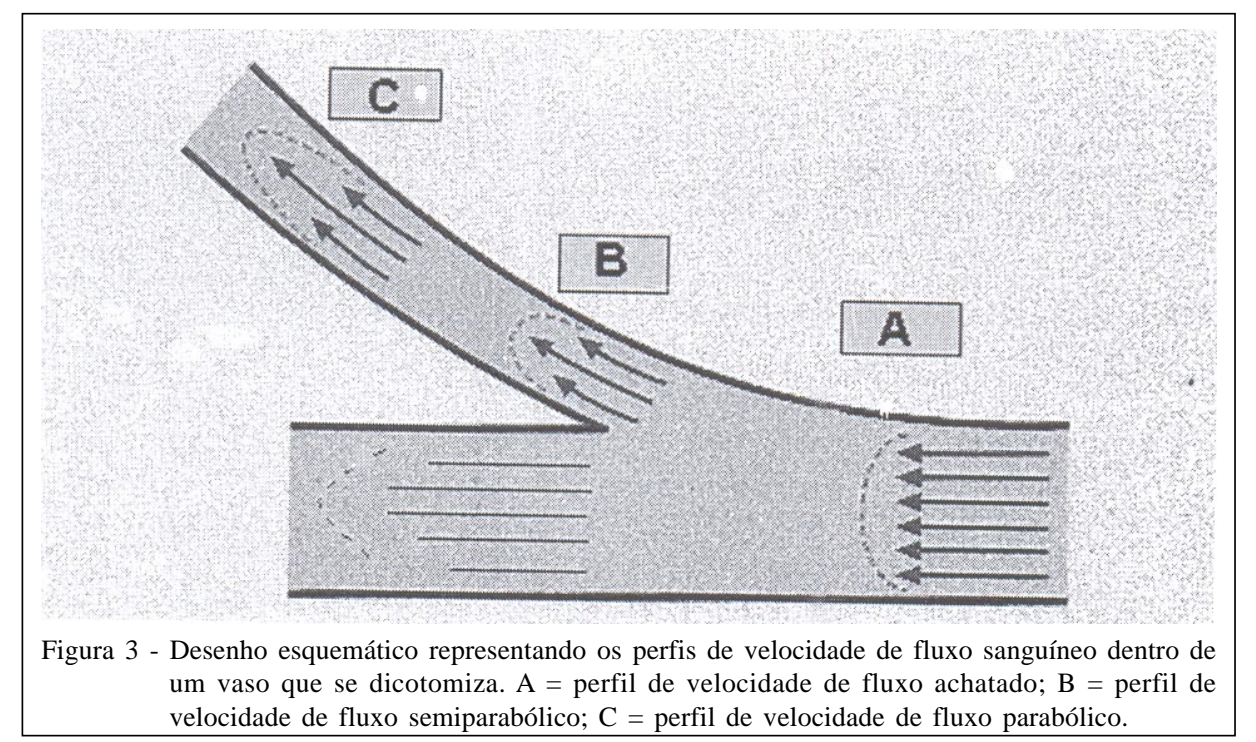

Ciência Rural, v.38, n.3, mai-jun, 2008. 
reverso (SZATMARI et al., 2001; NYLAND \& MATTOON, 2002). O mapeamento espectral pode demonstrar diversos padrões de fluxo. São eles:

Padrão de fluxo de alta resistividade: alta pulsatilidade e alta resistividade de fluxo são observadas através da presença de picos sistólicos finos (afilados) e fluxo reverso no início da diástole (ex.: aorta) (CERRI et al., 1998; SZATMARI et al., 2001); Padrão de fluxo de baixa resistividade: baixa pulsatilidade e baixa resistividade de fluxo são caracterizadas pela presença de picos sistólicos amplos e contínuos e alta velocidade de fluxo na diástole com velocidade decrescente. As artérias de baixa resistividade (ex.: artéria renal) suprem órgãos que possuem uma demanda contínua de sangue (CERRI et al., 1998; SZATMARI et al., 2001);

Padrão de fluxo de resistividade intermediária: fluxos de pulsatilidade e resistividade intermediária são evidenciados pela presença de picos sistólicos afilados (mais amplos do que os das artérias de padrão de alta resistividade) e fluxo direcional diastólico sem fluxo reverso (ex.: tronco celíaco). O pico de velocidade diastólico é mais baixo do que no padrão de fluxo de baixa resistividade quando comparado ao pico de velocidade sistólica (CERRI et al., 1998; SZATMARI et al., 2001);

Padrão de fluxo venoso: geralmente o fluxo nas veias é laminar. As condições de pressão intratorácica e intra-abdominal - durante a inspiração e expiração - influenciam a velocidade de fluxo sanguíneo nas veias, promovendo alterações de fase. A maioria das veias tem baixo grau de plasticidade e periodicidade. As veias hepáticas e a região cranial da veia cava caudal têm padrão Doppler com forte periodicidade por causa do efeito da pressão atrial direita exercida durante o ciclo cardíaco (CERRI et al., 1998; SZATMARI et al., 2001).

\section{Interpretação do espectro Doppler}

O monitor do espectro Doppler mostra informação do fluxo em função do tempo (NYLAND \& MATTOON, 2002). O tempo geralmente é disposto no eixo horizontal, e a frequiência de deslocamento (fd) ou a velocidade podem ser dispostas no eixo vertical (Figura 1). O traçado na linha de base horizontal no Doppler espectral indica o ponto zero de freqüência de deslocamento (ausência de fluxo) no eco retornado. Por convenção, o traçado espectral é disposto acima do zero da linha base, quando a frequiência do eco retornado é maior do que a freqüência transmitida e o fluxo segue na direção do transdutor. Um traçado disposto abaixo da linha base indica que o fluxo está direcionado no sentido contrário ao do transdutor e a freqüência retornada é menor do que a freqüência de insonação (NYLAND \& MATTOON, 2002). Aamplitude do espectro Doppler em qualquer ponto do tempo indica a variação das freqüências presentes. $\mathrm{O}$ aumento da amplitude determinado pelo alargamento espectral ocorre quando um número elevado de freqüências diferentes está presente em qualquer ponto particular (KAWAKAMA et al., 1993). Os transdutores têm a capacidade de calcular a média da freqüência de deslocamento ou a velocidade automaticamente (NYLAND \& MATTOON, 2002). O diâmetro do vaso e a velocidade do sangue podem variar durante o ciclo cardíaco ou com a respiração, o que é demonstrado no monitor do traçado espectral (KAWAKAMA et al., 1993; YANIK, 2002).

A largura do traçado indica a variação das velocidades presentes dentro do volume de amostra. A escala de cinza em qualquer porção do traçado representa o número relativo de células sanguíneas que viajam a uma velocidade particular, de forma que as áreas mais brancas representam o maior número de células sanguíneas (CERRI et al., 1998). A média de velocidade ou de deslocamento de freqüência é calculada automaticamente na maioria dos aparelhos de US Doppler. Os índices hemodinâmicos, como a relação sístole-diástole (S/D), o índice de resistividade (IR) e o índice de pulsatilidade (IP), permitem a comparação do fluxo durante a sístole e na diástole. Esses índices são utilizados para auxiliar na avaliação de estenose, trombose, ou, mais comumente, nos vasos periféricos com fluxo de resistência aumentada. Os índices mais utilizados são: índice de resistividade (AB/A) e índice de pulsatilidade (A-B/ Média). Baixas resistividades sugerem alto metabolismo e altas resistividades sugerem baixo metabolismo.

Quando existe fase negativa no traçado espectral, o índice de pulsatilidade é mais fidedigno. As alterações desses índices auxiliam na identificação de alterações na resistividade vascular associadas à rejeição de transplantes e a disfunções de parênquima, ou na caracterização de malignidade de doenças (CERRI et al., 1998; NYLAND \& MATTOON, 2002).

\section{CONCLUSÃO}

A compilação de todas as informações apresentadas neste artigo leva a concluir que é imprescindível conhecer os fundamentos da técnica Doppler para melhor entender a amplitude de suas aplicações, os resultados e as suas limitações técnicas. Assim, a detecção da arquitetura vascular, com determinação de padrão de fluxo sanguíneo, além da observação da direção e velocidade do sangue, permite 
guiar biópsias de tecidos de forma mais segura, evitando grandes vasos ou áreas de intensa vascularização. A técnica ainda auxilia na caracterização de massas tumorais e fornece informações sobre a hemodinâmica de diversos órgãos vitais. É uma técnica com aplicações promissoras nas áreas de medicina interna, vascular e oncologia veterinária.

\section{REFERÊNCIAS}

CERRI, G.G. et al. Avaliação dúplex do fígado, sistema portal e vasos viscerais. In: 1998. cap.6, p.120-121.

FEIGENBAUM, H. Instrumentation. In: Echocardiography. 4.ed. Philadelphia. Lea and Febiger, 1986 cap.1, p.1-49.

FINN-BODNER, S.T.; HUDSON, J.A. Abdominal vascular sonography. Veterinary Clinics of North America: Small Animal Practice, v.28, n.4, p.887-941, 1998.

KAWAKAMA, J. et al. Física. In: CERRI, G.G.; ROCHA, D.C. Ultra-sonografia abdominal. São Paulo: Sarvier, 1993. cap.1, p.1-14.
NYLAND, T.G.; MATTOON, J.S. Physical principles, instrumentation and ultrasound diagnosis safety. In:

Small animal diagnostic ultrasound. 2.ed. Philadelphia: Saunders, 2002. cap.1, p.1-19.

POULSEN NAUTRUP, C. Technical principles. In: POULSEN NAUTRUP, C.; TOBIAS, R. Diagnostic ultrasonography of the dog and cat. 2.ed. Hannover: Manson, 2001. p.31-59.

SPAULDING, K.A. A review of sonographic identification of abdominal blood vessels and juxtavascular organs. Veterinary Radiology and Ultrasound, v.38, n.1, p.4-23, 1997.

SZATMÁRI, V. et al. Normal duplex Doppler waveforms of major abdominal blood vessels in dogs: a review. Veterinary Radiology and Ultrasound, v.42, n.2, p.93-107, 2001.

VERMILLON, R.P. Basic physical principles. In: SNIDER, A.R. et al. Echocardiography in pediatric heart disease. 2.ed. Missouri: Mosby, 1997. cap.1, p.1-10.

YANIK, L. The basics of Doppler ultrasonography. Veterinary Medicine, v.3, p.388-400, 2002. 